Piwulang 8(1)(2020)
Teaching
http://journal.unnes.ac.id/sju/index.php/piwulang

\title{
PENGEMBANGAN BUKU PENGAYAAN TEKS DIALOG BANYUMASAN BERBASIS PITUTUR LUHUR PUPUH GAMBUH UNTUK SISWA KELAS VIII SMP
}

\author{
Meyla Nur Hayati ${ }^{1}$, Yusro Edy Nugroho ${ }^{2}$, Sucipto Hadi Purnomo ${ }^{3}$ \\ 1,2,3 Jurusan Bahasa Jawa, Fakultas Bahasa dan Seni, Universitas Negeri Semarang, Indonesia \\ Corresponding Author: meylanurhayati29@gmail.com ${ }^{1}$
}

\begin{abstract}
Abstrak
Tujuan penelitian ini adalah (1) mendeskripsikan kebutuhan siswa dan guru bahasa Jawa SMP di Kabupaten Banyumas terhadap buku pengayaan teks dialog Banyumasan berbasis pitutur luhur pupuh Gambuh, (2) membuat draft prototipe buku pengayaan teks dialog Banyumasan berbasis pitutur luhur pupuh Gambuh, dan (3) mendeskripsikan hasil validasi prototipe buku pengayaan teks dialog Banyumasan berbasis pitutur luhur pupuh Gambuh. Metode yang digunakan dalam penelitian ini yaitu metode Research and Development (R\&D). Tahap pengembangan buku pengayaan teks dialog Banyumasan berbasis pitutur luhur pupuh gambuh mengacu pada langkah Sugiyono (2010:409) yang disesuaikan dengan kebutuhan penelitian, yaitu: (1) potensi dan masalah, (2) pengumpulan data, (3) desain produk, (4) validasi produk, dan (5) revisi produk. Penelitian ini menghasilkan buku pengayaan teks dialog Banyumasan berbasis pitutur luhur pupuh gambuh.
\end{abstract}

Kata Kunci: Buku Pengayaan, teks Dialog, dialek Banyumasan, Serat Wulangreh pupuh Gambuh

\begin{abstract}
The objectives of this study are (1) to describe the needs of Javanese junior high school language students and teachers in Banyumas on the Banyumasan dialogue text enrichment book based on sublime pupuh Gambuh, (2) to make a prototype draft Banyumasan dialogue text enrichment book based on sublime pupuh Gambuh, and (3) describe the results of the prototype validation of Banyumasan dialogue text enrichment book based on sublime pupuh Gambuh. The method used in this study is the Research and Development $(R \& D)$ method. The development phase of the Banyumasan dialog text enrichment book based on the sublime pupuh gambuh pitur refers to the steps of Sugiyono (2010: 409) which are tailored to the research needs, namely: (1) potential and problems, (2) data collection, (3) product design, (4) product validation, and (5) product revisions. This study produced a Banyumasan dialog text enrichment book based on the pitutur luhur pupuh gambuh.
\end{abstract}

Keywords: Enrichment Book, Dialog Text, Banyumasan dialect, Serat Wulangreh pupuh Gambuh

(C) 2020 Universitas Negeri Semarang

p-ISSN 2252-6307

e-ISSN 2714-867X 
Meyla Nur Hayati, dkk/ Piwulang 8 (1) (2020)

\section{PENDAHULUAN}

Pembelajaran bahasa Jawa tingkat SMP kelas VIII semester gasal, kurikulum 2013 memuat materi teks legenda, piwulang Serat Wulangreh pupuh Gambuh, teks berita, memahami teks dialog dan sebagainya. Salah satu materi ajar yang mengandung banyak pesan moral adalah Serat Wulangreh pupuh Gambuh.

Serat Wulangreh merupakan salah satu hasil karya Jawa klasik berbentuk puisi tembang macapat, dalam bahasa Jawa baru ditulis tahun 1768-1820 oleh Pakubuwana IV yang isinya berbicara tentang keharusan-keharusan menghayati dan mengikuti etik kekratonan yang telah terlembagakan. Serat ini merupakan salah satu percikan semangat kekratonan dan gambaran pola pemikiran raja tentang masalah yang berkaitan dengan politik, pemerintahan, kekuasaan serta etika yang tak lepas dari pandangan masyakat Jawa secara umum (Zuhri 2015).

Tembang gambuh mempunyai arti jumbuh/sarujuk/cocok, yang artinya sudah cocok antara laki-laki dan perempuan yang memiliki rasa saling mencintai. Tembang gambuh memiliki 17 pada (bait), 5 gatra (baris) dengan guru wilangan dan guru lagu $7 \mathrm{u}, 10 \mathrm{u}, 12 \mathrm{i}$, $8 \mathrm{u}, 8 \mathrm{o}$. Nilai yang terkandung dalam tembang Gambuh adalah dalam manusia menuju kesempurnaan hidup manusia hendaknya memperahatikan dan mengamalkan pitutur luhur (nasehat) baik dari siapapun asalnya, dan meninggalkan nasehat yang salah walaupun dari orang tuanya. Tidak berwatak adigang, adingung dan adiguna artinya manusia tidak bersifat menonjolkan kegesitan dalam bertindak, kekuatan tubuh dan kesaktian, serta kepandaiannya. Dengan kata lain manusia hendaknya bersikap sabar, tidak tergesa-gesa dan berhati-hati (Widiyono 2010).

Pada setiap tembang macapat terdapat pitutur luhur yang mengajarkan manusia harus bersikap dengan sesama manusia maupun manusia dengan pencipta. Banyak amanat atau pitutur luhur yang terkandung dalam Serat Wulangreh antara lain yang menejelaskan bagaimana manusia bersikap dengan lingkungan, dengan masyarakat, dengan Tuhannya, tata karma, larangan-larangan, serta orang hidup harus menjaga lisan dan perbuatannya. Dengan mempelajari amanat dalam tembang macapat Serat Wulangreh diharapkan siswa dapat bersikap baik dalam kehidupan sehari-hari serta mematuhi norma-norma yang berlaku di masyarakat Jawa.

Pitutur luhur atau amanat dalam Serat Wulangreh terdapat dalam kurikulum 2013 pada tingkat SMP/MTs/SMLB kelas delapan semester gasal atau semester satu pada kompetensi dasar 3.2 menelaah teks piwulang Serat Wulangreh pupuh Gambuh dan 4.2 menanggapi teks piwulang Serat Wulangreh pupuh Gambuh. Dalam kompetensi dasar tersebut, siswa diharapkan mampu menelaah serta menanggapi teks Serat Wulangreh pupuh Gambuh dalam bentuk menjawab pertanyaan, menyampaikan amanat secara lisan maupun tertulis, memberi contoh perilaku yang mencerminkan pitutur luhur dalam Serat Wulangreh pupuh Gambuh dan dapat menembangkan tembang gambuh. Namun pada kenyataan dilapangan, peneliti menemukan 
Meyla Nur Hayati, dkk/ Piwulang 8 (1) (2020)

masalah yang terjadi pada pembelajaran bahasa Jawa mengenai matei Serat Wulangreh pupuh Gambuh. Materi tersebut dianggap materi yang sulit bagi siswa. Hal ini dapat dibuktikan berdasarkan hasil wawancara guru mata pelajaran bahasa Jawa di daerah Banyumas. Presentase siswa yang dapat menjawab pertanyaan Mengenai Serat Wulangreh pupuh Gambuh tidak lebih dari 30\%.

Berdasarkan hasil wawancara awal, menurut guru mata pelajaran bahasa Jawa di SMP Negeri 2 Kembaran dan SMP Gunungjati mengatakan bahwa faktor utama kendala yang muncul yang dihadapi adalah siswa tidak memahami bahasa yang digunakan dalam tembang gambuh, hal ini karena dialek bahasa Jawa yang digunakan pada buku teks berbeda dengan dialek Banyumasan. Dalam berbicara dengan guru saja mereka kesulitan apalagi bahasa tembang yang banyak menggunakan kata arkais. Faktor kedua yaitu kurangnya media pembelajaran atau buku yang menunjang siswa dalam mempelajari tembang Gambuh. Dalam pembelajaran berlangsung, guru hanya menggunakan buku teks, pepak atau tembang Gambuh yang berupa rekaman. Siswa hanya mencatat guru lagu, guru wilangan, serta guru gatra pada salah satu bait tembang saja. Selain itu, sekolah juga tidak memfasilitasi buku teks sesuai jumlah siswa, sehingga siswa hanya mendapatkan materi dari guru dan latihan soal pada LKS. Oleh karena itu, perlu adanya inovasi bagaimana Serat Wulangreh pupuh Gambuh dapat dipelajari dengan mudah. Berdasarkan hal tersebut, solusi yang ditawarkan adalah mengembangkan buku pengayaan berisi teks dialog Banyumasan berbasis pitutur luhur pupuh Gambuh bagi kelas VIII.

Buku pengayaan di masyarakat sering dikenal dengan istilah buku bacaan atau buku perpustakaan. Menurut Muslich (2014), buku bacaan yaitu buku yang memuat kumpulan bacaan, informasi, atau uraian yang dapat memperluas pengetahuan dan wawasan peserta didik pada bidang tertentu. Sedangkan Pusat Perbukuan Depdiknas (2008:6) mendefinisikan bahwa buku pengayaan merupakan buku yang memuat materi yang dapat memperkaya dan meningkatkan ketrampilan, membentuk kepribadian peserta didik, pengelola pendidikan, serta masyarakat umum lainnya.

Tarigan (2008) menjelaskan bahwa dialog merupakan pertukaran pikiran atau pendapat mngenai suatu topik tertentu antara dua atau lebih pembaca. Senada dengan Mulyana (2005:53), wacana dialog merupakan jenis wacana yang dituturkan oleh dua orang atau lebih. Jenis wacana ini berbentuk tulis maupun lisan. Dalam wacana dialog bentuk kedudukannya sama dengan wacana drama (Dialog skenario, dialog lawakan, kethoprak dan sebagainya.

Pemakaian bahasa Jawa dialek Banyumas meliputi Karesidenan Banyumas yaitu meliputi empat Kabupaten antara lain Kabupaten Banyumas, Kabupaten Cilacap, Kabupaten Purbalingga, dan Kabupaten Banjarnegara. Dialek Banyumas juga dipakai di daerah- daerah yang dahulunya pernah masuk wilayah kekuasaan para bupati Banyumas seperti daerah Gombong, Kebumen, dan Karanganyar (Koderi : 1991). 
Meyla Nur Hayati, dkk/ Piwulang 8 (1) (2020)

Berdasarkan latar belakang tersebut, rumusan masalah dalam penelitian ini, yaitu (1) bagaimana kebutuhan siswa dan guru terhadap buku pengayaan teks dialog Banyumasan berbasis pitutur luhur pupuh Gambuh untuk siswa kelas VIII SMP di Kecamatan Kembaran, (2) bagaimana prototipe buku pengayaan teks dialog Banyumasan berbasis pitutur luhur pupuh Gambuh untuk siswa kelas VIII SMP, dan (3) bagaimana validasi prototipe buku pengayaan teks dialog Banyumasan berbasis pitutur luhur pupuh Gambuh untuk siswa kelas VIII SMP.

Tujuan penelitian ini adalah mendeskripsikan kebutuhan siswa terhadap buku pengayaan teks dialog Banyumasan berbasis pitutur luhur pupuh Gambuh, membuat draf prototipe buku pengayaan teks dialog Banyumasan berbasis pitutur luhur pupuh Gambuh untuk siswa kelas VIII SMP dan mendeskripsikan hasil validasi prototipe buku pengayaan teks dialog berbasis pitutur luhur pupuh Gambuh untuk siswa kelas VIII SMP.

\section{METODE PENELITIAN}

Penelitian ini merupakan jenis penelitian Research and Developmenr (R\&D). Menurut Sugiyono, terdapat sepuluh langkah, yaitu (1) potensi dan masalah, (2) pengumpulan data, (3) desain produk, (4) validasi desain, (5) revisi desain, (6) uji coba produk, (7) revisi produk, (8) uji coba pemakaian, (9) revisi produk, dan (10) produksi massal.

Berdasarkan kebutuhan penelitian, langkah-langkah penelitian menurut Sugiyono disederhanakan menjadi lima tahapan, yaitu (1) potensi dan masalah, (2) pengumpulan data (analisis kebutuhan), (3) desain produk (penyusunan draf), (4) validasi desain (uji ahli), (5) revisi desain.

Data yang dibutuhkan dalam penelitian ini yaitu, amanat dalam Serat Wulangreh pupuh Gambuh, data kebutuhan siswa dan guru, dan data uji validasi. Sumber data yang diperoleh dari siswa, guru, Serat Wulangreh pupuh Gambuh (Marsudi Basa lan Sastra Jawa kelas VIII Kurikulum 2013), dan dosen ahli materi dan media. Teknik pengumpulan data dilakukan dengan cara observasi, wawancara, angket, telaah cerkak dan lembar penilaian uji ahli. Observasi dilakukan guna menemukan potensi dan masalah terkait ketersediaan buku teks dialog Banyumasan berbasis Serat Wulangreh, khususnya pupuh Gambuh. Wawancara dilakukan kepada guru guna mengetahui proses pembelajaran mengenai materi Serat Wulangreh pupuh Gambuh serta untuk mengetahui kebutuhan terhadap penyusunan buku pengayaan teks dialog Banyumasan berbasis Serat Wulangreh pupuh Gambuh. Angket digunakan untuk menjaring data analisis kebutuhan penyusunan buku pengayaan teks dialog Banyumasan berbasis Serat Wulangreh pupuh Gambuh. Lembar penilaian uji ahli dan media digunakan untuk mendapatkan penilaian maupun saran dari produk yang dihasilkan. Teknik analisis data yang digunakan adalah teknik analisis deskriptif kualitatif.

\section{HASIL DAN PEMBAHASAN}


Meyla Nur Hayati, dkk/ Piwulang 8 (1) (2020)

Hasil dan pembahasan meliputi (1) deskripsi karakteristik kebutuhan buku pengayaan teks dialog Banyumasan bebasis pitutur luhur pupuh Gambuh, (2) Prototipe buku pengayaan teks dialog Banyumasan bebasis pitutur luhur pupuh Gambuh, dan (3) Validasi dan perbaikan prototipe buku pengayaan teks dialog Banyumasan bebasis pitutur luhur pupuh Gambuh.

\section{Karakteristik Kebutuhan Buku}

Pemaparan karakteristik kebutuhan buku pengayaan teks dialog Banyumasan bebasis pitutur luhur pupuh Gambuh terdiri dari deskripsi kebutuhan siswa dan guru. Kebutuhan siswa dan guru terhadap pengembangan buku pengayaan teks dialog Banyumasan bebasis pitutur luhur pupuh Gambuh diperoleh dari dua sekolah yaitu SMP Negeri 2 Kembaran dan SMP Gunungjati.

Kebutuhan siswa terhadap pengembangan buku pengayaan teks dialog Banyumasan bebasis pitutur luhur pupuh Gambuh meliputi tiga aspek yaitu (1) tanggapan siswa mengenai materi Serat Wulangreh pupuh Gambuh, (2) tanggapan mengenai adanya pengembangan buku pengayaan teks dialog Banyumasan berbasis pitutur luhur pupuh Gambuh, dan (3) karakteristik buku pengayaan teks dialog Banyumasan berbasis pitutur luhur pupuh Gambuh. Adapun kebutuhan guru terhadap pengembangan buku pengayaan teks dialog Banyumasan berbasis pitutur luhur pupuh Gambuh meliputi (1) proses pembelajaran Serat Wulangreh pupuh Gambuh, (2) mengenai media yang digunakan dalam menyampaikan materi Serat Wulangreh pupuh Gambuh, (3) tanggapan mengenai pengembangan buku pengayaan teks dialog Banyumasan berbasis pitutur luhur pupuh Gambuh dan (4) karakteristik pengembangan buku pengayaan teks dialog Banyumasan berbasis pitutur luhur pupuh Gambuh.

\section{Prototipe Buku Pengayaan Teks Dialog Banyumasan}

Hasil analisis kebutuhan siswa dan guru terhadap buku pengayaan teks dialog Banyumasan bebasis pitutur luhur pupuh Gambuh disesuaikan dan dipertimbangkan guna penyusunan prototipe. Dari hasil analisis tersebut, dihasilkan prototipe buku teks dialog Banyumasan yang berjudul "Pacelathon Banyumasan" dengan ukuran dengan ukuran 17, 6 × $25 \mathrm{~cm}$ (B5). Jenis huruf yang digunakan adalah Comic Sans MS dengan ukuran huruf 13. Buku dicetak dengan menggunakan kertas HVS dan Soft. Secara keseluruhan buku pengayaan teks dialog ini kurang lebih berjumlah 64 halaman. Selain itu, buku ini dilengkapi dengan cover bergambar yang berfungsi sebagai icon tiap sub judul dan agar siswa mudah memahami. Bagian buku pengayaan teks dialog Banyumasan bebasis pitutur luhur pupuh gambuh terdiri dari tiga bagian, yaitu, pendahuluan, isi dan penyudah. Hal tersebut sesuai dengan teori yang dikemukakan oleh Muslich (2010: 302-303).

Mengacu pada teori Djajasudarma (2010:2) bahwa para ahli umumnya berpendapat bahwa wacana merupakan satuan gramatikal tertinggiyang direalisasikan dalam bentuk karangan yang utuh dengan amanat lengkap dengan koherensi dan kohesi tinggi, maka 
Meyla Nur Hayati, dkk/ Piwulang 8 (1) (2020)

penyusunan buku teks dialog Banyumasan berbasis pitutur luhur pupuh Gambuh diambil dari kata-kata yang terdapat tembang Gambuh. Kata per kata, bait per bait diartikan dan dipadukan. Setelah diartikan dan dipadukan maka dapat disimpulkan menjadi sebuah urutan sebuah cerita.

Bagian pendahu buku teks dialog berbasis pitutur luhur pupuh gambuh terdiri dari sampul depan, halaman judul, halaman hak cipta, prakata, serta daftar isi (Muslich, 2010: 302-303). Halaman sampul terdiri dari sampul depan dan belakang. Sampul depan didesain dengan ilustrasi gambar sesuai tembang gambuh yaitu nasehat orang tua kepada anaknya. Sementara sampul belakang berisi deskripsi buku dengan judul buku. Adapun halaman judul dan halaman hak cipta. Halaman judul berisi judul, sub judul dan nama penulis. Adapun halaman hak cipta berisi judul, sub judul, nama penulis buku, dan editor. Pada halaman kata pengantar juga dilengkapi penjelasan mengenai buku teks dialog Banyumasan, ucapan terimakasih serta harapan terhadap pembaca semoga buku yang ditulis penulis dapat bermanfaat. Adapun bagian daftar isi memuat sub judul beserta halaman yang terdapat buku pengayaan untuk memudahkan pembaca mencari dan mengetahui bagian keseluruhan isi buku pengayaan teks dialog Banyumas.

Bagian buku yang kedua yaitu bagian isi. Pada bagian isi, terdapat 2 bab yaitu; bab 1 mengenai tembang gambuh yang berjumlah 17 bait dengan terjemahan bahasa Jawa, bab ke 2 berisi dialog Banyumasan yang mengandung amanat Serat Wulangreh pupuh Gambuh.
Kemudian pada bagian pacelathon terdapat tujuh topik tersebut antara lain 1). Ora jujur bakal ajur, 2). Pitutur becik wajib dianut, 3) Adigang, adigung, lan Adigung, 4). Aja dadi pinter sing keblinger, 5). Reruba alaning wong, 6). Aji mumpung, 7) Aji mumpung, dan 8). Gedhe rumangsa. Ketujuh topik tersebut merupaka nhasil pengklasifikasian dari 17 pada/ bait tembang Gambuh. Berikut penjelasan setiap topik cerita;

Ora Jujur Bakal Ajur. Judul tersebut mewakili bait pertama dan kedua pada tembang Gambuh. Subab tersebut menceritakan atau menyampaikan amanat bahwa perilaku yang tidak jujur tidak akan mujur atau akan mendapatkan kerugian pada diri sendiri. Dalam topik atau subab ini terdapat dua pacelathon atau dialog yang berjudul Tukang Nyonto dan Ngindhari Ukuman.

Pitutur Becik Wajib Dianut. Judul tersebut mewakili bait ke tiga pada tembang Gambuh. Subab tersebut menceritakan atau menyampaikan amanat bahwa amanat atau nasihat baik patut ditiru meskipun amanat tersebut dari kalangan bawahan. Dalam topik atau subab ini terdapat dua pacelathon atau dialog yang berjudul Kebanan dan Ilmu Sekang Buku Bekasan.

Adigang, adigung, lan Adigung. Judul tersebut mewakili bait empat sampai sepuluh pada tembang Gambuh. Subab tersebut menceritakan atau menyampaikan amanat bahwa manusia tidak boleh mempunyai watak yang sombong. Adigang, adigung, dan adiguna adalah penggambaran watak yang menyombongkan kekuatan, kepintaran dan kedudukan. Dalam topik atau subab ini 
Meyla Nur Hayati, dkk/ Piwulang 8 (1) (2020)

terdapat dua pacelathon atau dialog yang berjudul Dhuwit Segala-Galane dan Jarkoni (Ngajari Tapi Ora Nglakoni).

Aja Dadi Pinter Sing Keblinger. Judul tersebut mewakili bait sebelas dan duabelas. Subab tersebut menceritakan atau menyampaikan amanat bahwa manusia yang senang disanjung, dimanj, dipuji serta diungkap kebaikannya nantinya bisa menyesatkan diri sendiri. Dalam topik atau subab ini terdapat dua pacelathon atau dialog yang berjudul Keblinger dan Si Master Basket.

Reruba Alaning Wong. Judul tersebut mewakili bait tiga belas. Subab tersebut menceritakan atau menyampaikan amanat bahwa orang senang dipuji sebanarnya sangat sederhana keinginannya yaitu untuk menyenangkan dirinya sendiri dan menjual keburukan orang lain. Dalam topik atau subab ini terdapat dua pacelathon atau dialog yang berjudul Kembang Kadho Ulang Taun dan Bullying.

Aji Mumpung. Judul tersebut mewakili bait empat belas dan lima belas. Subab tersebut menceritakan atau menyampaikan amanat bahwa untuk dengan atasan atau orang baik, semua cara akan dilakukan. Kemudian akan membuat ulah dengan menjual kemapuan orang lain. Selain itu orang yang mendorong seseorang untuk berbuat jahat. Dalam topik atau subab ini terdapat dua pacelathon atau dialog yang berjudul Milih Ketua Kelas dan Dadang Cupu.

Gedhe Rumangsa. Judul tersebut mewakili bait empat belas dan lima belas. Subab tersebut menceritakan atau menyampaikan amanat bahwa orang yang serba tau dan mengetahui semua padahal padahal yang mengetahui akan memalingkan muka dan tidak percaya lagi padanya. Dalam topik atau subab ini terdapat dua pacelathon atau dialog yang berjudul Mangan Dhuwit dan Sok Ngerti.

\section{Perbaikan dan Saran}

Prototipe buku pengayaan teks dialog Banyumas berbasis pitutur luhur pupuh gambuh telah uji validasi oleh ahli. Arahan dan bimbingan dari ahli digunakan untuk menyempurnakan buku pengayaan teks dialog Banyumasan menjadi bacaan yang lebih baik dan layak untuk dibaca. Buku tersebut dinilai oleh ahli materi dan ahli media.

\section{Perbaikan Ahli Materi}

Hasil dari penilaian ahli materi menunjukan bahwa buku pengayaan teks dialog Banyumas berbasis pitutur luhur pupuh gambuh sudah baik namun terdapat beberapa saran dari ahli untuk perbaikan. Perbaikan tersebut meliputi diksi, kalimat, EYD dan tata tulis supaya lebih diperhatikan.

\section{Perbaikan Ahli Media}

Perbaikan dan saran dari ahli media antara lain pewarnaan pada datar isi perlu diganti dari warna asal yang berwarna putih dengan warna dasar hijau tosca maka akan terlihat soft atau mati, dosen ahli menyarankan agar warna tulisan diganti yang lebih tua atau gelap. Selain itu, gradasi pada layout kurang hidup maka dosen ahli menyarankan agar warna dinaikan. Pada sampul belakang sebelum perbaikan hanya berisi deskripsi buku tanpa judul buku, dosen ahli menyarankan agar diberi judul paada sampul belakang. 
Meyla Nur Hayati, dkk/ Piwulang 8 (1) (2020)

\section{SIMPULAN}

Berdasarkan hasil penelitian yang telah dipaparkan diatas, maka terdapat beberapa simpulan sebagai berikut. Berdasarkan analisis kebutuhan terhadap buku pengayaan teks dialog Banyumas berbasis pitutur luhur pupuh gambuh, siswa dan guru membutuhkan buku pengayaan teks dialog Banyumas berbasis pitutur luhur pupuh gambuh sebagai penunjang pembelajaran khususnya pada kompetensi dasar 3.2 menelaah teks piwulang Serat Wulangreh pupuh Gambuh dan 4.2 menanggapi teks piwulang Serat Wulangreh Pupuh Gambuh.

Anatomi buku pengayaan ini meliputi bagian pendahuluan, isi, dan penyudah. Bagian pendahuluan meliputi sampul, halaman judul, halaman hak cipta, kata pengantar, dan daftar isi. Pada bagian isi buku "Pacelathon Banyumasan" berisi materi tentang serat wulangreh pupuh gambuh, tembang gambuh dan tujuh topik dialog yang telah diklasifikasikan yang bejudul ; Ora Jujur Bakal Ajur, Pitutur Becik Wajib Dianut, Adigang Adigung Adiguna, Aja Dadi Pinter Sing Keblinger, Reruba Alaning Wong, Aji Mumpung, Gedhe Rumangsa. Pada setiap topik mempunyai dua teks dialog. Selanjutnya, bagian penyudah yang berisi daftar pustaka, profil penulis, dan uraian singkat tentang buku yang diletakan di sampul belakang. Buku tersebut dibuat dengan ukuran 17, 6 × 25 cm (B5).

Berdasarkan uji ahli materi dan ahli media, buku pengayaan teks dialog Banyumas berbasis pitutur luhur pupuh gambuh sudah baik dan layak digunakan dalam pembelajaran.
Namun terdapat beberapa kekurangan yang harus diperbaiki. Saran dari dosen ahli materi yaitu perbaiki kata, EYD, diksi yang kurang tepat, serta pada penyajian buku supaya ditambahi dengan pengertian mengenai serat wulangreh. Saran dari dosen media yaitu mengenai warna tulisan yang kurang tepat pada daftar isi, serta pada sampul belakang agar ditambahkan judul buku.

Berdasarkan hasil penelitian tersebut, diharapkan buku pengayaan teks dialog Banyumas berbasis pitutur luhur pupuh Gambuh dapat dijadikan refernsi dan digunakan sebagai pelengkap buku teks dalam pelajaran bahasa Jawa. Penelitian ini masih jauh dari kata sempurna, bagi peneliti selanjutnya diharapkan dapat melanjutkan penelitian tentang buku pengayaan tentang teks dialog berbasis tembang gambuh agar jauh lebih baik lagi.

\section{DAFTAR PUSTAKA}

Departemen Pendidikan Nasional Republik Indonesia. 2008. Peraturan Menteri Pendidikan Nasional No. 2 Tahun 2008. Jakarta: Departemen Pendidikan Nasional Republik Indonesia.

Djajasudarma, Fatimah T. 20010. Wacana Pemahaman Dan Hubungan Antarunsur. Bandung: Refika Aditama.

Mulyana. 2015. Kajian Wacana Teori, Metode, dan Aplikasi Prinsip-prinsip Analisa Wacana. Yogyakarta: Tiara Wacana

Muslich, Masnur. 2010. Text Book Writing. Yogyakarta : Ar Ruzz Media. 
Meyla Nur Hayati, dkk/ Piwulang 8 (1) (2020)

Koderi, M. 1991. Banyumas Wisata Dan Budaya. Purwokerto: CV. Metro Jaya

Sugiyono. 2010. Metode Penelitian Kuantitatif, Kualitatif, dan R\&D. Bandung: Alfabeta.

Tarigan, Henry Guntur. 2008. Membaca Sebagai Suatu Keterampilan Berbahasa. Bandung: Angkasa.

Zuhri. 2005. Etika Kewarganegaraan Dalam Serat Wulangreh. Jurnal Kebudayaan. Vol 10.No 1.

Widiyono, Yuli. 2010. Kajian Tema, Nilai Estetika, dan

Pendidikandalam Serat Wulangreh Karya Sri Susuhunan Pakubuwana IV. Tesis. Solo : Pendidikan Bahasa Indonesia. UNS. 